\title{
Modelo interdisciplinar para análise teórica da ação da escola na promoção do desenvolvimento à escala humana
}

\author{
Interdisciplinary model for the theoretical analysis of school action in the \\ promotion of human scale development
}

\section{Modelo interdisciplinario para análisis teórico de la acción de la escuela en la promoción del desarrollo a escala humana}

\author{
Claudio Roberto Stacheira ${ }^{1}$ \\ Ana Maria Nogales Vasconcelos ${ }^{2}$ \\ Neusa Maria Ravaroto ${ }^{1}$ \\ Leides Barroso Azevedo Moura²
}

Recebido em 08/11/2018; revisado e aprovado em 14/04/2019; aceito em 06/05/2019

DOI: http://dx.doi.org/10.20435/inter.v21i1.2227

\begin{abstract}
Resumo: O presente artigo pressupõe a relação ecológica e interdisciplinar entre escola e desenvolvimento e apresenta um modelo teórico, denominado MIATAE, para estudá-la. Identifica elementos de convergência entre as teorias do Desenvolvimento à Escala Humana, a Perspectiva Freireana de Educação e a Teoria Bioecológica do Desenvolvimento Humano. O trabalho baseou-se no método dialético, com natureza analítica e abordagem qualitativa. Utilizou técnica de revisão narrativa de literatura, com análise apoiada em critérios de caráter histórico, teórico e metodológico. O MIATAE é composto por três polos com as funções axiológica, ontológica e topológica, exercidas, respectivamente, pelas teorias admitidas. Também possui uma morfologia entre elas que prospecta quatro relações teóricas interdisciplinares, diante do objeto de interesse de análise representado por um núcleo. Conclui que uma destas, a Relação Interdisciplinar Completa, revela uma nova síntese teórica sobre a ação da escola na promoção do Desenvolvimento à Escala Humana, que amplia as possibilidades de compreensão de sua interdisciplinaridade. Essa relação também transcende o enfoque particular de cada teoria admitida, conservando a epistemologia disciplinar potencializada a essa análise. Admitidos os limites do presente trabalho, o MIATAE possibilita à escola evidenciar e sustentar teoricamente o propósito, o conteúdo e a estratégia de sua ação na direção do Desenvolvimento à Escala Humana, de maneira interdisciplinar estruturada.
\end{abstract}

Palavras-chave: educação; políticas públicas; projeto educativo; relações ecológicas.

Abstract: The present article presupposes the ecological and interdisciplinary relation between school and development and presents a theoretical model, MIATAE, to study it. It identifies elements of theoretical convergence between Human Scale Development, the Freirean Education Perspective and the Bioecological Theory of Human Development. The study was based on the dialectical method, with an analytical nature and qualitative approach. It used a narrative literature review technique, with analysis based on historical, theoretical and methodological criteria. MIATAE is composed of three poles with the axiological, ontological and topological function exercised, respectively, by the accepted theories. It also has a morphology between them that prospects four interdisciplinary theoretical relations, before the object of analysis interest represented by a nucleus. It concludes that one of these, the Complete Interdisciplinary Relationship, reveals a new theoretical synthesis about the school's action in the promotion of the Human Scale Development, which expand the possibilities of understanding its interdisciplinarity. This relationship also transcends the particular focus of each theory admitted, conserving the disciplinary epistemology potentiated to this analysis. Within the limits of the present work, MIATAE allows the school to evidence and theoretically sustain the purpose, content and strategy of its action to Human Scale Development, in a structured interdisciplinary approach. Keywords: education; public policy; educational project; ecological relationships.

Resumen: El presente artículo presupone la relación ecológica e interdisciplinaria entre escuela y desarrollo y presenta un modelo teórico, denominado MIATAE, para su estudio. Identifica elementos de convergencia entre las teorías del Desarrollo a Escala Humana, Perspectiva Freireana de Educación y Teoría Bioecológica del Desarrollo Humano. El trabajo fue basado en el método dialéctico, con naturaleza analítica y enfoque

\footnotetext{
${ }^{1}$ Universidade Estadual de Goiás (UEG), Anápolis, Goiás, Brasil.

2 Universidade de Brasília (UNB), Brasília, Distrito Federal, Brasil.
} 
cualitativo. Utilizó técnica de revisión narrativa de literatura, con análisis apoyado en criterios de carácter histórico, teórico y metodológico. El MIATAE está compuesto por tres polos con las funciones axiológica, ontológica y topológica, ejercidas, respectivamente, por las teorías admitidas. También tiene una morfología que prospecta cuatro relaciones teóricas interdisciplinares entre ellas, frente al objeto de interés de análisis representado por un núcleo. Concluye que una, la Relación Interdisciplinaria Completa, revela una nueva síntesis teórica sobre la acción de la escuela en la promoción del Desarrollo a Escala Humana, que amplía las posibilidades de comprensión de su interdisciplinaridad. Esta relación también trasciende el abordaje particular de cada teoría admitida, conservando la epistemología disciplinaria potencializada en este análisis. EI MIATAE posibilita a la escuela evidenciar y sostener teóricamente el propósito, el contenido y la estrategia de su acción hacia el Desarrollo a Escala Humana, de manera interdisciplinaria estructurada.

Palabras clave: educación; políticas públicas; proyecto educativo; relaciones ecológicas.

\section{INTRODUÇÃO}

O Desenvolvimento à Escala Humana (DEH) é uma proposta teórica apresentada por Manfred Max-Neef no ano de 1986, com a colaboração de Antonio Elizalde e Martin Hopenhayn. Sugere "uma teoria das necessidades humanas fundamentais e uma concepção de desenvolvimento que rompe radicalmente com as visões dominantes que o posicionam como um objeto análogo ao crescimento econômico" (ELIZALDE, 2000, p. 51).

Em seus estudos, Chirinos e Gonzáles (2006), Meyer (2013) e Tapia (2014) consideram o DEH entre os enfoques pós-coloniais e as teorias que reorientam o desenvolvimentismo. Segundo Max-Neef (2012), a ideia-força do DEH assume o ser humano como sujeito do desenvolvimento. Para o autor, essa concepção ampara-se em três pilares: i) reconhecimento e satisfação das necessidades humanas fundamentais; ii) geração crescente de autodependência; e iii) construção e manutenção de relações de interdependência entre seres humanos, natureza e tecnologia, processos globais e comportamentos locais, bem como entre as dimensões pessoal e social, planejamento e autonomia e sociedade civil e Estado (MAX-NEEF, 2012).

Na proposta do DEH, esses pilares sustentam-se pela criação de condições nas quais as pessoas sejam protagonistas do seu próprio futuro (MAX-NEEF, 2012). Essa base é um ponto fundamental de convergência entre o DEH e a educação. Além de ser um direito que dá acesso a outros direitos (SACRISTÁN, 2015), a educação é admitida no presente trabalho como um processo que contribui para gerar as condições que o DEH precisa.

A sinergia é ainda mais relevante quando considerada a Perspectiva Freireana de Educação (PFE), na qual as pessoas são assumidas como sujeitos do processo educativo, e a educação, um ato de intervenção no mundo para a formação da consciência crítica destes indivíduos e para a transformação social positiva da realidade (FREIRE, 1996; 2011; 2016; 2017).

A partir das proposições de Gadotti (1992), Casassus (2002), Canário (2005; 2006), Meksenas (2014), Lück (2011) e Freire (1996; 2011), a escola é considerada um elemento estruturante para a educação das novas gerações e para a promoção do desenvolvimento, diante dos múltiplos fatores que compõem o processo educativo. Assim como a PFE favorece a evidência da relação entre escola e desenvolvimento, a ecologia que os aglutina pode ser explicada pela Teoria Bioecológica do Desenvolvimento Humano (TBDH). Proposta por Urie Bronfenbrenner, a TBDH é um enfoque da psicologia do desenvolvimento construído ao longo da segunda metade do século XX e início do XXI. Para ela, o desenvolvimento humano é resultado da interação entre a pessoa, o contexto em que ela vive e se desenvolve, o processo entre ela e esse contexto e o tempo (BRONFENBRENNER, 2011; BENETTI et al., 2013). Na perspectiva da 
TBDH, o indivíduo desenvolve-se e influencia o desenvolvimento do seu contexto, simultânea e mutuamente.

Nessa perspectiva, o presente trabalho assumiu existir potencial de convergência entre estas três teorias, que conserva a epistemologia original e as potencializa para a análise da relação entre a ação da escola e a promoção do DEH. No entanto, mesmo reconhecida a consistência de cada uma para análises pelo seu ponto de vista, admitiu-se também que sozinhas elas não explicam a complexidade inerente a essa relação. Sendo assim, como articular estas três teorias e compreender a ação da escola na promoção do DEH, em uma perspectiva interdisciplinar estruturada? Propôs-se que a análise dessa relação a partir da interdisciplinaridade entre DEH, PFE e TBDH pode revelar uma nova síntese teórica que transcende o enfoque isolado de cada teoria. Assim, o objetivo do presente artigo foi propor um modelo interdisciplinar para análise teórica da ação da escola na promoção do DEH.

\section{METODOLOGIA}

O presente trabalho assumiu as obras matriciais do DEH, da PFE e da TBDH, acompanhadas de literatura científica correlacionada, enquanto seu conjunto de dados. Em seu delineamento, utilizou aspectos teórico-metodológicos encontrados em Jupiassu (2006) e Minayo (2010) acerca da interdisciplinaridade, complexidade e construção dialógica do conhecimento. A pesquisa baseou-se no método dialético, tendo natureza analítica e abordagem qualitativa. No aspecto técnico, utilizou revisão narrativa de literatura, com análise apoiada em critérios de ordem histórica, teórica e metodológica.

O trabalho percorreu quatro etapas: i) definição dos critérios de seleção e revisão de literatura, bem como de análise de convergência entre as teorias admitidas; ii) seleção e análise de bibliografia publicada em periódicos indexados pela Capes nas duas últimas décadas, em complemento às obras matriciais de cada teoria de base; iii) análise dos pontos de intersecção entre DEH, PFE e TBDH a partir dos critérios predefinidos; e iv) síntese do modelo proposto, elicitando a interdisciplinaridade entre as teorias e a relação em estudo.

\section{RESULTADOS E DISCUSSÃO}

\subsection{Escola e desenvolvimento: uma relação ecológica}

De acordo com Canário (2006, p. 27), a escola é "sem dúvida, uma das mais importantes instituições educativas". Sua concepção, funcionamento e resultados são influenciados pela visão de sociedade e pelo contexto em que ela está inserida (FREIRE, 1996; CASASSUS, 2002). Segundo Sibilia (2012, p. 16), "a escola foi concebida com o objetivo de atender a um conjunto de demandas específicas do projeto histórico de modernidade que a planejou e procurou pô-la em prática". Assim, tornou-se instrumento principal do modelo de desenvolvimento ocidental hegemônico, cujo sistema educativo escolar localiza nela o centro de sua ação. Para Canário (2006, p. 17), isso expõe a escola à subordinação instrumental de uma "racionalidade econômica que está na raiz dos nossos graves problemas sociais".

Apesar disso, a escola contém atributos que permitem superar tal condição. Corroborando com a PFE, Casassus (2002, p. 62) indica que "a forma de existência de uma escola é dada por um fluxo de interações entre pessoas". Canário (2006) e Lück (2011) reforçam esse aspecto, 
destacando a natureza dinâmica, histórica e dialógica da escola e de seus processos educativos, intra e extraescolares, com os quais a ação escolar se manifesta na direção de uma perspectiva de desenvolvimento que vença a concepção bancária de educação (CANÁRIO, 2006; FREIRE, 2017). Esses atributos superam a noção que simplifica a identidade da escola a fatores explícitos, como infraestrutura, pessoal, currículo e recursos administrativos, pois "não é possível à escola, se, na verdade, engajada na formação de educandos educadores, alhear-se das condições sociais culturais, econômicas de seus alunos, de suas famílias, de seus vizinhos" (FREIRE, 1996, p. 63).

Esse é o ponto central da ecologia da relação entre a escola e o desenvolvimento: a escola deve promover uma educação "entendida em um sentido amplo como um processo de conhecer e intervir no mundo, uma contribuição decisiva para que possamos encontrar uma 'saída' para as questões de civilização que nos atingem" (CANÁRIO, 2006, p. 12). Nessa relação, reconhece-se a interdependência entre a escola, o contexto, o ser humano enquanto sujeito da ação escolar e a dimensão local como seu vetor, própria também do DEH. Essa noção sistêmica da relação entre a escola, seus sujeitos e seu contexto ao longo do tempo aproxima a TBDH, a PFE e o DEH. De acordo com Canário (2006, p. 19), os processos de mudança promovidos a partir da ação escolar são ecológicos, pois "a escola e seus atores mudam em um mesmo tempo e por interação recíproca". De acordo com Gadotti (1992, p. 43) e Lück (2011, p. 95), a escola "é um organismo vivo". Para tal, sua ação admite um dado modelo de desenvolvimento como paradigma pelo qual reconhece os sujeitos de seu processo educativo, interpreta o contexto e projeta sua ação e seus resultados sobre ele e a sociedade. Tais autores ainda reconhecem nessa interatividade a dinâmica em que se manifesta a práxis educativa prevista na PFE. Isso implica ação e reflexão das pessoas sobre o mundo para transformá-lo, pois o "homem só se humaniza no processo dialógico de humanização do mundo" (FREIRE, 2017, p. 26). A mesma visão integra a TBDH, que se encontra no centro das finalidades da ação escolar na PFE e também do DEH.

\subsection{Convergência entre as teorias admitidas para a composição do modelo}

Considerando o objetivo do presente trabalho, o quadro a seguir evidencia os pontos de intersecção entre o DEH, a PFE e a TBDH, com base nos critérios definidos para o estudo. 
Quadro 1 - Análise de intersecção entre as teorias admitidas na composição do modelo

\begin{tabular}{|c|c|c|c|}
\hline \multirow[b]{2}{*}{ CRITÉRIOS } & \multicolumn{3}{|c|}{ TEORIAS } \\
\hline & $\begin{array}{l}\text { Desenvolvimento à } \\
\text { Escala Humana }\end{array}$ & $\begin{array}{c}\text { Perspectiva Freireana de } \\
\text { Educação }\end{array}$ & $\begin{array}{c}\text { Teoria Bioecológica do } \\
\text { Desenvolvimento Humano }\end{array}$ \\
\hline $\begin{array}{l}\text { Área do } \\
\text { conhecimento }\end{array}$ & Economia ecológica. & Pedagogia. & $\begin{array}{c}\text { Psicologia do } \\
\text { desenvolvimento. }\end{array}$ \\
\hline $\begin{array}{l}\text { Contexto em } \\
\text { que surge e se } \\
\text { desenvolve }\end{array}$ & $\begin{array}{l}\text { Década de 1970, em } \\
\text { meio aos debates } \\
\text { sobre a finitude dos } \\
\text { recursos naturais } \\
\text { do planeta, o papel } \\
\text { da economia na } \\
\text { sociedade, o lugar do } \\
\text { ser humano nesse } \\
\text { processo e o futuro } \\
\text { da América Latina. }\end{array}$ & $\begin{array}{c}\text { Década de 1960, na } \\
\text { origem de um novo } \\
\text { paradigma educativo. Brasil, } \\
\text { diante de seus dramas } \\
\text { nacionais do pós-guerra. } \\
\text { Percurso histórico desde } \\
\text { o desenvolvimentismo, } \\
\text { passando pelo período } \\
\text { de regime militar, } \\
\text { redemocratização e } \\
\text { pós-Constituição de } 1988 \text {. }\end{array}$ & $\begin{array}{l}\text { Final da década de } 1970 \\
\text { nos EUA, com revisões e } \\
\text { incrementos constantes } \\
\text { até o início dos anos } 2000 . \\
\text { Baseada nas complexas } \\
\text { experiências de vida, } \\
\text { estudos e práticas de } \\
\text { pesquisa de seu autor } \\
\text { nas áreas de psicologia, } \\
\text { educação infantil e políticas } \\
\text { públicas. }\end{array}$ \\
\hline $\begin{array}{l}\text { Ideia-força que } \\
\text { defende }\end{array}$ & $\begin{array}{c}\text { "O desenvolvimento } \\
\text { se refere a pessoas, } \\
\text { não a objetos" (MAX- } \\
\text { NEEF, 2012). }\end{array}$ & $\begin{array}{c}\text { A educação, uma forma } \\
\text { permanente de intervenção } \\
\text { no mundo, liberta o ser } \\
\text { humano da condição de } \\
\text { oprimido. Ninguém educa } \\
\text { ninguém: as pessoas } \\
\text { educam-se mutuamente } \\
\text { (FREIRE, 1996; 2016; 2017). }\end{array}$ & $\begin{array}{l}\text { "O desenvolvimento é } \\
\text { definido como mudança } \\
\text { duradoura na maneira } \\
\text { como a pessoa percebe e } \\
\text { lida com seu ambiente" } \\
\text { (BRONFENBRENNER, } \\
\text { 2011). }\end{array}$ \\
\hline $\begin{array}{l}\text { Lugar do ser } \\
\text { humano na teoria }\end{array}$ & $\begin{array}{l}\text { Sujeito do processo } \\
\text { de desenvolvimento. }\end{array}$ & $\begin{array}{c}\text { Sujeito do processo } \\
\text { educativo. }\end{array}$ & $\begin{array}{c}\text { Sujeito do processo de } \\
\text { desenvolvimento humano. }\end{array}$ \\
\hline $\begin{array}{l}\text { Método científico } \\
\text { que a caracteriza }\end{array}$ & Dialético. & Dialético. & $\begin{array}{c}\text { Fenomenológico e } \\
\text { dialético. }\end{array}$ \\
\hline
\end{tabular}

Fonte: Baseado na Tese de Doutorado do primeiro autor.

Conforme demonstrado no Quadro 1, existe convergência entre as teorias admitidas para a composição do modelo ora proposto a partir do contexto em que surgiram, da ideia-força que defendem, da forma como o ser humano é assumido e do método científico que fundamenta cada uma. Ao mesmo tempo, as interfaces reveladas por estes critérios asseguram os atributos originais de cada teoria. Associadas à diversidade em relação às áreas de conhecimento, tais características produzem uma heterogeneidade necessária à análise teórica interdisciplinar.

Segundo Jupiassu (2006, p. 5), a presença de fatores de convergência e de afirmação disciplinar é uma condição essencial para a interdisciplinaridade, que "se realiza nas fronteiras e pontos de contato entre diversas ciências". Minayo (2010, p. 441) reforça essa visão e complementa que o refinamento disciplinar é fundamental à convergência pretendida. Dessa forma, cada teoria deve ser compreendida em sua dimensão específica para que o modelo interdisciplinar seja construído a partir do olhar original, gerando uma nova visão sobre o objeto, que não se apresenta pelo enfoque disciplinar isolado. 


\subsection{Desenvolvimento à Escala Humana (DEH)}

O DEH assume que o melhor processo de desenvolvimento é aquele que permite a elevação da qualidade de vida das pessoas, o equilíbrio dos sistemas naturais e a superação das desigualdades internas locais (MAX-NEEF, 2012).

Segundo Elizalde (2000), Chirinos e Gonzáles (2006) e Ballesteros (2010), o DEH gera uma nova configuração no sistema de valores das pessoas e da sociedade. Nessa epistemologia, a pessoa humana e a garantia de vida são a razão de ser do modelo e do processo de desenvolvimento. O ser humano é sujeito indissociável de um sistema integral de vida. A noção de desenvolvimento como ação polarizada entre centro e periferia dá lugar a uma visão em que a autodependência e a ação local são fundamentais às articulações orgânicas. O equilíbrio ecológico dos sistemas humanos se contrapõe ao gigantismo artificial predominante na economia, no modelo de cidades e de desejos humanos. Para Max-Neef (2007), esse gigantismo extrapola os limites da condição natural da vida, promove o consumo em massa e reproduz um aspecto mecanicista de justiça social inspirada no paradigma da eficiência, que se confunde com o próprio crescimento econômico e condena o humano a ser objeto do processo. Se o modelo de desenvolvimento hegemônico concentra-se na perpetuação do sistema econômico como fim, no DEH ele é meio e sua finalidade é a interdependência orgânica entre vida e ambiente.

De acordo com Elizalde (2000) e Max-Neef (2012), o DEH possui três postulados: i) o desenvolvimento se refere a pessoas, não a objetos; ii) as necessidades humanas são finitas, poucas e classificáveis; e iii) as necessidades humanas são as mesmas ao longo da história. Para Elizalde (2000), isso pode ser visto como um sistema composto por três subsistemas que interagem mutuamente: das necessidades, dos satisfatores ${ }^{3}$ e dos bens. No primeiro, tais autores constroem uma taxonomia com nove necessidades humanas fundamentais - não hierárquicas, a não ser diante da necessidade de sobrevivência: subsistência, proteção, afeto, entendimento, participação, ociosidade, criação, identidade e liberdade. Elas são as mesmas para todas as pessoas ao longo da história e em todas as culturas. No segundo subsistema, os satisfatores "são as formas históricas e culturais mediante as quais damos conta de nossas necessidades humanas fundamentais" (ELIZALDE, 2000, p. 52). Trata-se de formas humanas individuais ou coletivas de Ser, Ter, Fazer e Estar, que definem o sistema de valores que uma cultura ou sociedade atribui às suas necessidades. No terceiro, os bens econômicos são definidos como "objetos ou artefatos que afetam a eficiência de um satisfator, alterando os limites de satisfação de uma necessidade, tanto positiva como negativamente" (MAX-NEEF, 2012, p. 39).

Juntos, esses elementos constituem uma Matriz de Necessidades Humanas Fundamentais e Satisfatores, principal componente metodológico do DEH. Ela torna explícita, por exemplo, a diferença semântica do termo "necessidade", na visão do DEH, em comparação ao significado no modelo de desenvolvimento análogo ao crescimento econômico: enquanto a saúde física é considerada uma necessidade no modelo hegemônico, no DEH é assumida como um satisfator possível para a necessidade humana fundamental de subsistência, na forma humana de Ser.

De acordo com Max-Neef (2012, p. 40), na perspectiva do DEH, "se por um lado os bens econômicos são capazes de afetar a eficiência dos satisfatores, por outro serão determinantes na geração daqueles". Segundo o autor, é por meio desta "causação recíproca" que eles se tornam parte e definição de uma cultura que, à sua dinâmica, determina o estilo de desenvolvimento.

\footnotetext{
${ }^{3}$ Termo/conceito original utilizado por Max-Neef (2012), como parte das proposições do DEH.
} 
Logo, a Matriz não esgota o elenco de satisfatores possíveis às necessidades classificadas. Ao contrário, amplia seu potencial metodológico em processos de diagnóstico, planejamento e avaliação de ações de pequena até larga escala em matéria de desenvolvimento humano. Isso favorece a aplicação do DEH do nível local ao global, tendo o indivíduo, seus grupos ou instituições como unidades específicas ou integradas de análise (BALLESTEROS, 2010).

\subsection{Perspectiva Freireana de Educação (PFE)}

A história recente da educação brasileira é influenciada pelo pensamento e pelas obras de Paulo Freire, considerado um dos mais notáveis pensadores da pedagogia mundial (BROCK; SCHWARTZMAN, 2005; SHIGUNOV NETO, 2015; PILETTI; PILETTI, 2016).

Para Freire (1996, p. 98), "a educação, como experiência especificamente humana, é uma forma de intervenção no mundo". Ela está relacionada à condição e à "consciência do inacabamento entre nós" (FREIRE, 1996, p. 56). Como ser inconcluso, o homem é um ser histórico e necessita da educação como evento permanente para formá-lo consciente em relação ao mundo e a si próprio, diante de sua condição inacabada. A educação é, nesse sentido, um movimento constante deste sujeito em busca da consciência de sua condição, do mundo e do seu papel transformador, de si mesmo e da realidade (FREIRE, 1996; FREIRE; OLIVEIRA, 2016).

$\mathrm{Na} P F E$, os seres humanos são sujeitos responsáveis por si próprios, pelos seus pares e pelo contexto em que vivem, da dimensão local até a global. Para Freire (1996, p. 56), isso implica "eticidade de nossa presença no mundo". De acordo com o autor, "o mundo não é. O mundo está sendo" (FREIRE, 1996, p. 76). Isso ressalta a compreensão dialógica que está no cerne da PFE. Nela, o papel do ser humano vai além de somente constatar o que ocorre na realidade, alcançando a ação crítica sobre esta, como sujeito histórico da ação educativa.

A PFE também evidencia o ser humano como um ser de relações. Admite ainda a educação como seu processo de transformação positiva e da realidade (FREIRE, 2011) que, diante da complexidade inerente ao desenvolvimento humano, deve criar condições favoráveis e promover a consciência crítica e a ação ética junto ao sujeito do processo educativo. Nesse sentido, a educação deve possibilitar a inserção, discussão e ação humana sobre a realidade pessoal, comunitária, profissional, cívica nacional e do mundo (FREIRE, 2011; 2017).

Assim, a educação é também política. Para Freire (2011, p. 110), "a raiz mais profunda da politicidade da educação se acha na educabilidade mesma do ser humano, que se funda na sua natureza inacabada e da qual se tornou consciente". Dessa forma, ao longo do tempo o ser humano se faz um ser ético, de opção e de decisão em favor do equilíbrio da vida.

Nessa proposição, a educação deve ser um processo emancipatório, diferente do modelo de formação escolar industrial em massa. Segundo Freire (2017), o treinamento característico do modelo de sociedade ocidental atual não forma, e sim domestica o indivíduo, pois uma de suas finalidades é a preparação de mão de obra para o mercado. Trata-se da concepção bancária de educação evidenciada pelo autor na epistemologia do oprimido. Na contramão da PFE, ela visa sustentar um discurso fatalista para "convencer os prejudicados das economias submetidas de que a realidade é assim mesmo e de que não há nada a fazer além de seguir a ordem dos fatos" (FREIRE, 2011, p. 127).

A PFE concebe uma educação para o desenvolvimento e para a democracia, para a responsabilidade social e para a política (GADOTTI, 1992; FREIRE, 1996; 2016; 2017). De acordo 
com Freire (2017, p. 88), "o desenvolvimento envolve não apenas questões técnicas ou de política puramente econômica ou de reformas de estruturas, mas guardando em si, também, a passagem de uma para outra mentalidade". Esse aspecto também pode ser encontrado em Gadotti (1992), Canário (2005) e Lück (2011), reforçando a relação entre a escola, sua ação e a promoção do desenvolvimento.

\subsection{Teoria Bioecológica do Desenvolvimento Humano (TBDH)}

A TBDH considera que o desenvolvimento humano é resultado da interação entre quatro elementos inter-relacionados: a Pessoa; seu Contexto de vida; o Processo entre ela e esse contexto; e o Tempo (BRONFENBRENNER, 1996; 2011; BENETTI et al., 2013).

O elemento Pessoa compreende as dinâmicas e características do ser humano em processo de desenvolvimento ao longo do curso de vida, tais como valores, comportamento, visão de mundo e expectativas. Para Bronfenbrenner (2011), elas exercem considerável influência nas experiências do indivíduo e no contexto em que ele vive. Também devem ser consideradas as características sociodemográficas, pois podem influenciar esse processo. Para o autor, nenhum atributo do indivíduo pode existir ou exercer influência sobre o desenvolvimento de forma isolada (BRONFENBRENNER, 2011).

Já o elemento Contexto admite que o indivíduo em desenvolvimento está inserido em um ambiente formado por um sistema ecológico de camadas interconectadas, composto por Microssistema, Mesossistema, Exossistema, Macrossistema e Cronossistema. Segundo Bronfenbrenner (2011, p. 19), esse ambiente "é um local onde as pessoas podem interagir reciprocamente face a face e, especialmente no curso de uma atividade conjunta, o que $A$ faz influencia B e vice-versa" (BRONFENBRENNER, 2011, p. 19). Para Dessen e Costa Junior (2005) e Benetti et al. (2013), o Microssistema pode ser entendido como sendo os ambientes em que o indivíduo está envolvido em relações diretas (família ou escola, por exemplo). O Mesossistema concentra inter-relações entre os ambientes onde o indivíduo vive de forma ativa (vizinhança ou entre ramos da família, por exemplo). Já no Exossistema esse mesmo indivíduo não participa ativamente, mas pode ser influenciado por eventos que nele ocorram ou vice-versa (local de trabalho dos pais, por exemplo). Por sua vez, o Macrossistema concentra as interconexões entre os demais ambientes, que variam de uma cultura para outra e podem impactar os indivíduos e seus contextos (mudanças no regime político e crises econômicas, por exemplo). Juntas, estas camadas formam "uma organização de encaixe de estruturas concêntricas interdependentes, em que uma está contida na seguinte" (BRONFENBRENNER, 1996, p. 18).

A interação entre Pessoa e Contexto caracteriza o terceiro elemento da TBDH: os Processos Proximais. Eles são a força motriz do desenvolvimento humano (DESSEN; COSTA JUNIOR, 2005; BRONFENBRENNER, 2011) e operam nas camadas ambientais ao longo do tempo. Para Bronfenbrenner (2011, p. 88), eles são analisados em termos de sistemas em que, iniciando em nível mais profundo, revelam a díade - ou o sistema de duas pessoas, como uma unidade mínima de interação e uma das unidades básicas de análise da TBDH. Para o autor, "um modelo de sistemas da situação imediata vai além da díade e atribui igual importância aos chamados sistemas N + 2 - tríades, tétrades e estruturas interpessoais mais amplas" (BRONFENBRENNER, 2011, p. 88). Na mesma perspectiva, as conexões entre outras pessoas presentes no contexto, sua natureza e sua influência indireta sobre a pessoa em desenvolvimento possuem igual importância, às quais 
também se aplica o princípio trídico. Assim, "a capacidade de um ambiente - o lar, a escola, o trabalho - funcionar efetivamente como um contexto para o desenvolvimento depende da existência e da natureza das conexões sociais entre ambientes" (BRONFENBRENNER, 1996; 2011).

Por fim, no Cronossistema, o Tempo trata da dimensão histórica e da progressividade necessária ao desenvolvimento humano, pois, para ser efetivo, o desenvolvimento deve ocorrer em uma base estável e por longos períodos (BRONFENBRENNER, 2011; BENETTI et al., 2013).

\subsection{A proposta de um novo modelo: Modelo Interdisciplinar para Análise Teórica da Ação da Escola na Promoção do DEH (MIATAE)}

A partir das características disciplinares e dos elementos de convergência entre o DEH, a PFE e a TBDH descritos acima, apresenta-se a seguir o Modelo Interdisciplinar para Análise Teórica da Ação da Escola na Promoção do DEH (MIATAE), proposto pelo presente trabalho.

O MIATAE é formado por núcleo, polos e relações, conforme ilustrado na Figura 1 a seguir. A disposição destes componentes é sistêmica e horizontal.

Figura 1 - Modelo interdisciplinar para Análise Teórica da Ação da Escola na Promoção do DEH (MIATAE)

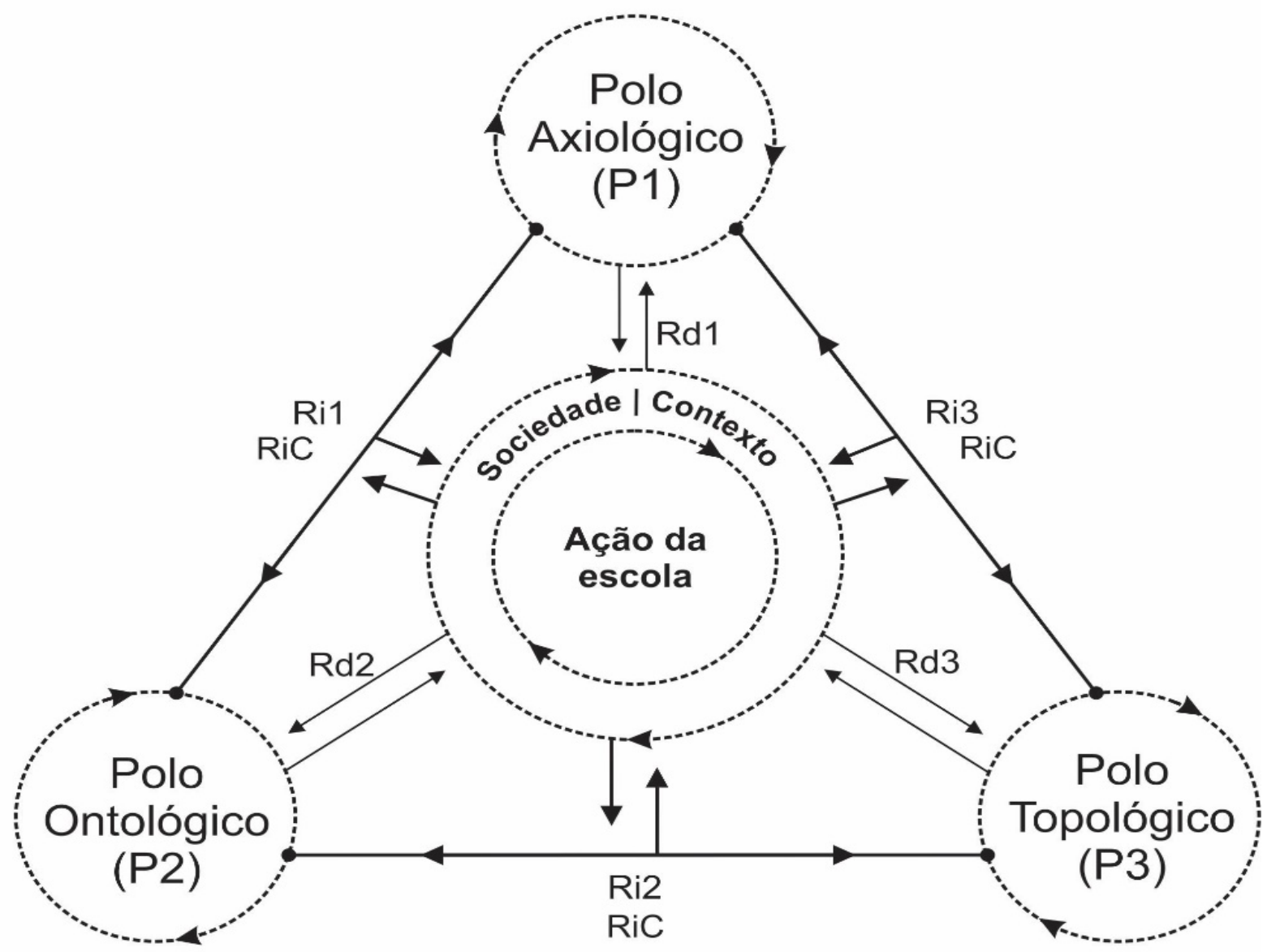

Fonte: elaboração própria. 
O núcleo é a representação da realidade que se deseja estudar. Ele simboliza a delimitação do objeto a ser analisado pelo modelo e é composto pelos ambientes interno e externo. 0 interno representa a ação da escola como um todo e dos membros da sua comunidade educativa, enquanto o externo diz respeito à sociedade/contexto/macrossistema da qual fazem parte e para onde seu legado educativo é destinado. A permeabilidade da borda representa a mútua influência entre os ambientes. As setas circulares em ambos significam a dinâmica viva e interativa entre a escola, os membros da comunidade educativa e o contexto em que agem e interagem.

Os polos são as lentes teóricas do modelo que permitem analisar a realidade a partir das funções que exercem sobre o núcleo. A noção funcional fundamenta-se na proposição de Bronfenbrenner (2011, p. 128), segundo o qual "encontra-se no centro do paradigma ecológico a visão de desenvolvimento como uma função articulada entre a pessoa e o contexto". Nesse sentido, o MIATAE possui três polos e as suas funções são Axiológica (P1), Ontológica (P2) e Topológica (P3).

A borda dos polos é permeável e possui movimento contínuo, indicando a natureza aberta, cíclica e interativa das teorias admitidas no MIATAE, assim como sua capacidade de renovação. Isso se dá por intermédio de Relações Disciplinares (Rd) e Interdisciplinares (Ri) constantes e dialógicas, pelas quais os polos interagem com o núcleo e entre si, sendo retroalimentados com atributos das demais teorias e da realidade em estudo, formando um encadeamento recíproco por onde as relações são geradas, circulam e difundem-se entre eles e o objeto. O encadeamento entre os três polos gera a Relação Interdisciplinar Completa (RiC) do MIATAE.

Uma vez definido o objeto a ser estudado, os polos/funções agem na configuração teórica do modelo, acoplando uma teoria em cada polo e analisando sua expressão disciplinar sobre ele. Conforme demonstrado no Quadro 2 a seguir, na configuração proposta pelo presente trabalho, o DEH é assumido como P1, a PFE como P2 e a TBDH como P3.

Quadro 2 - Configuração teórica do MIATAE

\begin{tabular}{|c|c|c|}
\hline Polo/Teoria & lave semântica & Função do polo sobre o núcleo \\
\hline $\begin{array}{c}\text { P1: Axiológico } \\
\text { (DEH) }\end{array}$ & $\begin{array}{c}\text { Para qual } \\
\text { perspectiva de } \\
\text { sociedade a } \\
\text { escola educa os } \\
\text { seus estudantes? }\end{array}$ & $\begin{array}{l}\text { Representa o paradigma de desenvolvimento e sociedade que a } \\
\text { escola assume como valor e que inspira sua ação educativa, anima } \\
\text { a execução e a transferência do seu legado. Corresponde ao projeto } \\
\text { de civilização que perpassa a ação de todos os agentes do processo } \\
\text { educativo, mobilizando sinergia na escola, na sociedade/contexto } \\
\text { e entre elas. }\end{array}$ \\
\hline $\begin{array}{c}\text { P2: Ontológico } \\
\text { (PFE) }\end{array}$ & $\begin{array}{c}\text { Qual perspectiva } \\
\text { de educação } \\
\text { fundamenta a } \\
\text { ação da escola? }\end{array}$ & $\begin{array}{l}\text { Representa a concepção de educação da ação escolar diante } \\
\text { da sociedade/contexto. Caracteriza o pensamento, o ambiente } \\
\text { educativo e as práticas didático-pedagógicas da escola, cultivadas } \\
\text { diariamente pelos agentes do processo educativo para a consecução } \\
\text { de seus objetivos. }\end{array}$ \\
\hline $\begin{array}{c}\text { P3: Topológico } \\
\text { (TBDH) }\end{array}$ & $\begin{array}{l}\text { Como a escola } \\
\text { configura sua } \\
\text { ação educativa? }\end{array}$ & $\begin{array}{l}\text { Representa a estratégia da escola para modelar e aplicar seu } \\
\text { processo educativo, de forma a responder aos desafios da } \\
\text { sociedade/contexto em que está inserida. Demonstra como a escola } \\
\text { reconhece e configura os elementos que geram o desenvolvimento } \\
\text { dos seus sujeitos e do contexto a que pertencem. }\end{array}$ \\
\hline
\end{tabular}

Fonte: elaboração própria. 
Para a configuração do MIATAE, cada polo utiliza uma chave semântica que decodifica sua função a partir da teoria que o caracteriza e orienta a análise do núcleo. Dessa forma, P1 representa a perspectiva de desenvolvimento e sociedade que a escola valoriza e assume para a educação de seus estudantes (Rd1). P2 exprime a concepção de educação que fundamenta a ação escolar (Rd2). Já P3 consiste na estratégia da escola para gerar os resultados de sua ação, junto aos sujeitos do processo educativo e à sociedade/contexto ( $R d 3$ ). Sendo assim, no enfoque disciplinar, a chave semântica e a função caracterizam os polos e explicam a relação disciplinar teórica mútua e dialogal entre cada um deles e o núcleo.

Após configurar o modelo, os polos/funções problematizam a ação da escola na promoção do DEH por meio das Ri e da RiC. Com isso, o MIATAE revela sua capacidade morfológica, gerando visões teóricas interdisciplinares sobre o objeto, descritas a seguir no Quadro 3.

Quadro 3 - Visões teóricas interdisciplinares geradas pelo MIATAE

\begin{tabular}{|c|c|c|}
\hline Relação & Chave semântica & Descrição \\
\hline $\begin{array}{c}\text { Ri1 } \\
\text { (P1P2) }\end{array}$ & $\begin{array}{l}\text { A concepção de } \\
\text { educação da ação } \\
\text { escolar favorece } \\
\text { a promoção do } \\
\text { DEH? }\end{array}$ & $\begin{array}{l}\text { Por meio da interdisciplinaridade entre o DEH e a PFE, O MIATAE } \\
\text { torna teoricamente explicita a intenção da ação escolar e o propósito } \\
\text { do seu resultado na sociedade/contexto. Também posiciona o ser } \\
\text { humano como sujeito do processo educativo e do desenvolvimento. } \\
\text { Essa visão evidencia a convergência na ação escolar entre o conteúdo } \\
\text { fundamentado na PFE e o projeto de civilização que o DEH sugere. }\end{array}$ \\
\hline $\begin{array}{c}\mathrm{Ri2} \\
\text { (P2P3) }\end{array}$ & $\begin{array}{l}\text { Os resultados } \\
\text { educacionais da } \\
\text { ação escolar são } \\
\text { satisfatórios? }\end{array}$ & $\begin{array}{l}\text { Por meio da interdisciplinaridade entre a PFE e a TBDH, O MIATAE } \\
\text { demonstra teoricamente a ausência de referência explícita que oriente } \\
\text { a geração de resultados e a transferência de legado da ação escolar } \\
\text { à sociedade/contexto, mesmo que o produto do processo educativo } \\
\text { alcance um patamar de desempenho e eficiência considerado } \\
\text { satisfatório pelo sistema educativo escolar formal. }\end{array}$ \\
\hline $\begin{array}{c}\text { Ri3 } \\
\text { (P1P3) }\end{array}$ & $\begin{array}{l}\text { A estratégia da } \\
\text { ação escolar } \\
\text { favorece a } \\
\text { promoção do } \\
\text { DEH? }\end{array}$ & $\begin{array}{l}\text { Por meio da interdisciplinaridade entre o DEH e a TBDH, O MIATAE } \\
\text { reconhece teoricamente a predisposição da ação escolar em } \\
\text { configurar e aplicar o processo educativo na direção do DEH. Essa visão } \\
\text { evidencia os atributos Processo e Tempo, indispensáveis à dinâmica de } \\
\text { desenvolvimento das pessoas, da sociedade/contexto e da escola na } \\
\text { direção do DEH. }\end{array}$ \\
\hline $\begin{array}{c}\mathrm{RiC} \\
(\mathrm{P} 1 \mathrm{P} 2 \mathrm{P} 3)\end{array}$ & $\begin{array}{l}\text { A ação da escola } \\
\text { promove o DEH? }\end{array}$ & $\begin{array}{l}\text { Por meio da interdisciplinaridade entre } \mathrm{DEH} \text {, PFE e TBDH, O MIATAE } \\
\text { oferece uma visão que permite configurar e analisar teoricamente a } \\
\text { ação da escola na direção do DEH. Nela, o DEH torna-se o paradigma } \\
\text { de vida ao qual a práxis educativa da PFE coaduna-se e orienta sua } \\
\text { intencionalidade, diante do sujeito humano e do contexto em que ele } \\
\text { vive e se desenvolve. Essa visão concebe um processo bioecológico de } \\
\text { desenvolvimento, em que as pessoas, a sociedade/contexto e a própria } \\
\text { comunidade escolar praticam mutuamente o DEH. }\end{array}$ \\
\hline
\end{tabular}

Fonte: elaboração própria.

De acordo com o MIATAE, para promover o DEH na sociedade/contexto, a ação da escola precisa evidenciar e fundamentar teoricamente o seu propósito (P1), seu conteúdo (P2) e sua estratégia (P3), de forma interdisciplinar a partir das proposições do DEH (P1), da PFE (P2) e da TBDH (P3) diante da realidade. Nessa visão, cada polo tem um significado complementar no modelo, que advoga pela necessidade de aplicar as três funções juntas para compreender teo- 
ricamente o objeto representado pelo núcleo, de maneira interdisciplinar, multidimensional e sistêmica. Logo, a aplicação do MIATAE baseando-se em apenas dois polos não proporcionaria a completude semântica da análise sobre o objeto pretendido: i) com P1 e P2, a ação escolar sabe onde quer chegar e dispõe do que fazer, mas falta-lhe a forma de organizar e colocar o trabalho em prática na direção pretendida; ii) com P2 e P3, a ação escolar possui conteúdo e estratégia, mas a latência de sua intencionalidade pode limitá-la a reproduzir o status quo da realidade; e iii) com P1 e P3, a ação escolar tem inspiração e potencial de realização, mas falta-lhe o conteúdo que materialize o respectivo objetivo no processo educativo.

A ausência do terceiro polo nas visões acima reduz a capacidade de o MIATAE analisar se a escola e os agentes de seu processo educativo dirigem-se ao DEH, especialmente às condições que esse paradigma preconiza. Porém isso não anula possíveis atributos funcionais complementares que estejam contidos nas teorias admitidas em seu estado disciplinar e que sejam vistos com potencial para preencher o polo ausente na relação. No entanto, na versão ora apresentada, uma mesma teoria não pode ocupar dois polos ao mesmo tempo, pois, se assim fosse, poderia diminuir a evidência de funções e principalmente de novas visões que a interação entre elas proporciona.

Ainda que possua características multifuncionais, no modelo proposto, uma teoria pode aproveitá-la somente no escopo da sua função, como ativo para melhor exercê-la. Isso não deve ser visto como limitação da proposta, pois se trata de uma condição necessária para revelar os limites e os pontos de conexão disciplinar que Jupiassu (2006) e Minayo (2010) destacam como necessários à interdisciplinaridade.

O modelo tampouco prevê visões teóricas híbridas geradas entre relação disciplinar e interdisciplinar. Com isso, são necessárias as três teorias para abastecê-lo. Esta pode ser vista como uma limitação, mas não reduz o potencial morfológico do MIATAE, tendo em vista que os métodos dialético e fenomenológico presentes nas teorias que o constituem e nele próprio permitem a interpretação flexível das visões em diferentes contextos da realidade.

No MIATAE, cada função refere-se a um fator explícito da ação da escola na promoção do DEH, seja para diagnóstico, seja para planejamento, monitoramento ou avaliação. Dessa forma, sua utilidade essencial é tornar evidentes e explícitos os fatores e as características nessa relação. Ao fazê-lo, permite analisá-la de maneira formal, estruturada, sistêmica e ecológica, tal como as teorias que o compõem.

Nesse sentido, nos limites teóricos da presente análise, ainda que de forma subjetiva, o MIATAE sugere que a visão interdisciplinar que permite a análise teórica de maior consistência sobre a ação da escola na promoção do DEH é a RiC. Contudo faz-se necessário testar sua validade por meio de pesquisa empírica, na qual o modelo teórico reflexivo proposto deve guiar a interpretação dos resultados obtidos, a partir da análise das variáveis selecionadas. A esse respeito, os autores consideram utilizar dados secundários de avaliações de larga escala da educação básica, produzidos e disponibilizados pelo governo federal brasileiro, em contribuição aos esforços multissetoriais de fortalecimento das políticas públicas desta área, mobilizados no marco do Plano Nacional de Educação (PNE). 


\section{CONCLUSÕES}

Ao responder ao objetivo desejado, o presente artigo conclui que MIATAE revela novas visões teóricas sobre a ação da escola na promoção do $D E H$, a partir da interdisciplinaridade estruturada entre DEH, PFE e TBDH.

Entre as visões elicitadas, o modelo sugere que a RiC possibilita a análise teórica interdisciplinar de maior consistência sobre o objeto de estudo pretendido, com a qual a escola pode evidenciar e fundamentar teoricamente o propósito, o conteúdo e a estratégia de sua ação na direção do DEH na sociedade/contexto. Entretanto, assumidos os limites do presente trabalho, considera-se necessário testar empiricamente a validade desta proposição, utilizando - MIATAE como guia para interpretar os resultados obtidos a partir da análise de variáveis selecionadas.

Conclui-se também que a capacidade morfológica presente no MIATAE amplia as possibilidades de explicação da complexidade inerente à ação da escola na promoção do DEH, transcendendo o enfoque particular de cada teoria admitida, ao mesmo tempo que conserva a epistemologia disciplinar e a potencializa nessa análise.

Nesse sentido, no MIATAE, a interdisciplinaridade estruturada entre DEH, PFE e TBDH para análise da ação da escola na promoção do DEH mostrou-se possível. O modelo favorece o enfoque e a compreensão do objeto de interesse em sua multidimensionalidade, com potencial para evidenciar teoricamente a relação entre escola e desenvolvimento.

\section{REFERÊNCIAS}

BALLESTEROS, Carlos. Economía a Escala Humana: una aproximación a los valores de la economía solidaria desde las ideas de Max-Neef. Revista Nuevas Tendencias en Antropología, n. 1, p. 89-107, 2010.

BENETTI, Idonézia C.; VIEIRA, Mauro Luis; CREPALDI, Maria Aparecida; SCHNEIDER, Daniela Ribeiro. Fundamentos da teoria bioecológica de Urie Bronfenbrenner. Pensando Psicología, v. 16, n. 9, p. 89-99, jan./dez. 2013.

BROCK, Colin; SCHWARTZMAN, Simon (Org.). Os desafios da educação no Brasil. Rio de Janeiro: Nova Fronteira, 2005.

BRONFENBRENNER, Urie. Bioecologia do desenvolvimento humano: tornando os seres humanos mais humanos. Porto Alegre: Artmed, 2011.

BRONFENBRENNER, Urie. A ecologia do desenvolvimento humano. Porto Alegre: Artmed, 1996

CANÁRIO, Rui. A escola tem futuro? Das promessas às incertezas. Porto Alegre: Artmed, 2006

CANÁRIO, Rui. O que é a Escola? Um "olhar" sociológico. Porto, Portugal: Porto Editora, 2005

CASASSUS, Juan. A escola e a desigualdade. Tradução de Lia Zatz. Brasília: Plano Editora, 2002.

CHIRINOS, Norbis M.; GONZALES, Sorayda R. Concepciones del desarrollo en el Siglo XX: estado y política social. Revista de Ciencias Sociales, Maracaibo, Venezuela, v. XII. n. 2, p. 205-22, maio/ago. 2006.

DESSEN, Maria Auxiliadora; COSTA JUNIOR, Áderson Luiz (Org.). A ciência do desenvolvimento humano: tendências atuais e perspectivas futuras. Porto Alegre: Artmed, 2005. 
ELIZALDE, Antonio. Desarrollo a escala humana: conceptos y experiencias. Interações: Revista Internacional de Desenvolvimento Local, Campo Grande, MS, v. 1, n. 1, p. 51-62, set. 2000.

FREIRE, Paulo. Pedagogia do oprimido. 64. ed. Rio de Janeiro/São Paulo: Paz e Terra, 2017.

FREIRE, Paulo. Educação como prática de liberdade. 41. ed. Rio de Janeiro/São Paulo: Paz e Terra, 2016.

FREIRE, Paulo. Educação e mudança. 34. ed. São Paulo: Paz e Terra, 2011.

FREIRE, Paulo. Pedagogia da autonomia: saberes necessários à prática educativa. São Paulo: Paz e Terra, 1996.

FREIRE, Ana Maria Araújo; OLIVEIRA, Walter Ferreira de Oliveira. Pedagogia da solidariedade. 2. ed. São Paulo: Paz e Terra, 2016.

GADOTTI, Moacir. Escola vivida, escola projetada. Campinas, SP: Papirus, 1992.

JUPIASSU, Hilton. O espírito interdisciplinar. Cadernos EBAPE/FGV, Rio de Janeiro, v. IV, n. 3, out. 2006.

LÜCK, Heloísa. Gestão da cultura e do clima organizacional da escola. 2. ed. Petrópolis, RJ: Vozes, 2011. (Série Cadernos de Gestão).

MAX-NEEF, Manfred A. Desenvolvimento a escala humana: concepção, aplicação e reflexões posteriores. Blumenau: Edifurb, 2012.

MAX-NEEF, Manfred A. La dimensión perdida: la deshumanización del gigantismo. Barcelona: Icaria, 2007.

MEKSENAS, Paulo. Sociologia da educação. Introdução ao estudo da escola no processo de transformação social. 17. ed. São Paulo: Edições Loyola, 2014.

MEYER, Raúl Gonzáles. Revisitando la historia de las teorías del desarrollo. Cultura-Hombre-Sociedad (CUHSO), Temuco, Chile, v. 23. n. 1. p. 55-91, jul. 2013.

MINAYO, Maria Cecília de Souza. Disciplinaridade, interdisciplinaridade e complexidade. Emancipação, Ponta Grossa, PR, v. 10, n. 2, p. 435-42, 2010.

PILETTI, Claudino; PILETTI, Nelson. História da Educação: de Confúcio a Paulo Freire. 1. ed., 3. reimp. São Paulo: Contexto, 2016.

SACRISTÁN, José Gimeno. Por que nos importamos com a educação no futuro? In: JARAUTA, Beatriz; IMBERNÓN, Francisco (Org.). Pensando no futuro da educação: uma nova escola para o século XXII. Porto Alegre: Penso, 2015.

SHIGUNOV NETO, Alexandre. História da educação brasileira: do período colonial ao predomínio das políticas educacionais neoliberais. São Paulo: Salta, 2015.

SIBILIA, Paula. Redes ou paredes: a escola em tempos de dispersão. Rio de Janeiro: Contraponto, 2012.

TAPIA, Carlos F. J. C. El concepto y la visión del desarrollo como base para la evaluación de políticas públicas. Economía y Sociedad, v. XVIII, n. 30, p. 47-65, jan./jun. 2014.

Sobre os autores: 
Claudio Roberto Stacheira: Doutor em Desenvolvimento, Sociedade e Cooperação Internacional pela Universidade de Brasília (UnB) - área de concentração: desenvolvimento e avaliação de políticas públicas. Mestre em Gestão do Conhecimento e da Tecnologia da Informação e especialista em Gestão de Projetos pela Universidade Católica de Brasília (UCB). Professor da Universidade Estadual de Goiás (UEG). Líder do Grupo de Pesquisa em Desenvolvimento e Tecnologias Aplicadas (GEDETEC/UEG). Instrutor da Escola de Governo do Estado de Goiás. Perfil e experiência interdisciplinar nas áreas acadêmica e de mercado. É consultor, pesquisa e leciona nas seguintes áreas: planejamento e desenvolvimento institucional; engenharia e gestão do conhecimento; gestão de organizações do conhecimento; desenvolvimento regional; gestão de projetos; gestão pública; políticas públicas; planejamento baseado em cenários prospectivos; sistemas de informações gerenciais; indicadores, estratégia e gestão. E-mail: claudio@stacheira.com, Orcid: http://orcid.org/0000-0001-6642-8091

Ana Maria Nogales Vasconcelos: Doutorado em Demografia pela Université Catholique de Louvain. Professora do Departamento de Estatística e professora do Programa de PósGraduação em Desenvolvimento, Sociedade e Cooperação Internacional (PPGDSCI/CEAM/ UNB). Coordenadora do Laboratório de População e Desenvolvimento com projetos na área da saúde e vulnerabilidade social, vinculado ao Núcleo de Estudos Urbanos e Regionais (NEUR/ CEAM) da Universidade de Brasília. Atua na área de demografia e estatística aplicada. Em seu currículo Lattes, os termos mais frequentes na contextualização da produção científica, tecnológica e artístico-cultural são: mortalidade, causas de morte, análise de correspondência, ensino de estatística, mortalidade infantil, violência, migração, projeções de população, crescimento demográfico, indicadores, educação e juventude. E-mail: ananogalesunb@gmail.com, Orcid: http://orcid.org/0000-0001-7589-107X

Neusa Maria Ravaroto: Mestre em Administração pelo Centro Universitário Alves Faria (UNIALFA). Especialista em Gestão de Projetos pela Universidade Católica de Brasília (UCB) e em Concessões e Parcerias na Administração Pública pelo Instituto Brasiliense de Direito Público (IDP). Analista governamental na Universidade Estadual de Goiás (UEG) e pesquisadora do Grupo de Pesquisa em Desenvolvimento e Tecnologias Aplicadas (GEDETEC/UEG). Desde o ano de 2015, é gerente de Convênios e Captação de Recursos da UEG. Possui experiência acadêmica e profissional nas áreas de estratégia e gestão, gestão pública, gestão de projetos, gestão de convênios e captação de recursos no setor público e em organizações da sociedade civil, desenvolvimento regional, desenvolvimento sustentável, políticas públicas, redes de cooperação entre setor empresarial X governo X universidade e inovação social. E-mail: neusa@ravaroto.com, Orcid: http://orcid.org/0000-0002-2726-6912

Leides Barroso Azevedo Moura: Pós-doutora pela University College London. Doutora em Ciências da Saúde pela Universidade de Brasília (UnB). Mestre em Ciências da Enfermagem pela Western Connecticut State University, nos Estados Unidos. Graduada em Enfermagem pela Universidade Federal de Mato Grosso (UFMT), licença registrada (RN) pelo New York Board of Education, nos Estados Unidos (2000-2019). Enfermeira de Saúde Pública do Departamento de Saúde de Nova York por seis anos. Professora associada da Universidade de Brasília. Licença internacional de Consultora em Lactação Humana (International Board of Lactation Consultant, 2005). Atuação nas seguintes áreas: saúde, território e determinantes sociais, políticas públicas, violências, curso de vida, saúde, educação e desigualdades, segurança alimentar e nutricional, envelhecimento 
e qualidade de vida, universidade promotora de saúde. E-mail: leidesm74@gmail.com, Orcid: http://orcid.org/0000-0002-1208-4569 